\title{
Cathepsin-S degraded decorin are elevated in fibrotic lung disorders - development and biological validation of a new serum biomarker
}

S.N. Kehlet ${ }^{1,4^{*}}$, C.L. Bager ${ }^{2}$, N. Willumsen ${ }^{1}$, B. Dasgupta ${ }^{3}$, C. Brodmerkel $^{3}$, M. Curran ${ }^{3}$, S. Brix ${ }^{4}$, D.J. Leeming ${ }^{1}$ and M. A. Karsdal ${ }^{1}$

\begin{abstract}
Background: Decorin is one of the most abundant proteoglycans of the extracellular matrix and is mainly secreted and deposited in the interstitial matrix by fibroblasts where it plays an important role in collagen turnover and tissue homeostasis. Degradation of decorin might disturb normal tissue homeostasis contributing to extracellular matrix remodeling diseases. Here, we present the development and validation of a competitive enzyme-linked immunosorbent assay (ELISA) quantifying a specific fragment of degraded decorin, which has potential as a novel non-invasive serum biomarker for fibrotic lung disorders.

Methods: A fragment of decorin cleaved in vitro using human articular cartilage was identified by mass-spectrometry (MS/MS). Monoclonal antibodies were raised against the neo-epitope of the cleaved decorin fragment and a competitive ELISA assay (DCN-CS) was developed. The assay was evaluated by determining the inter- and intra-assay precision, dilution recovery, accuracy, analyte stability and interference. Serum levels were assessed in lung cancer patients, patients with idiopathic pulmonary fibrosis (IPF), patients with chronic obstructive pulmonary disease (COPD) and healthy controls.

Results: The DCN-CS ELISA was technically robust and was specific for decorin cleaved by cathepsin-S. DCN-CS was elevated in lung cancer patients $(p<0.0001)$ and IPF patients $(p<0.001)$ when compared to healthy controls. The diagnostic power for differentiating lung cancer patients and IPF patients from healthy controls was 0.96 and 0.77 , respectively.

Conclusion: Cathepsin-S degraded decorin could be quantified in serum using the DCN-CS competitive ELISA. The clinical data indicated that degradation of decorin by cathepsin-S is an important part of the pathology of lung cancer and IPF.
\end{abstract}

Keywords: Decorin, Cathepsin-S, Extracellular matrix, Cancer, Idiopathic pulmonary fibrosis, Serum biomarker

\footnotetext{
* Correspondence: snk@nordicbio.com

${ }^{1}$ Nordic Bioscience A/S, Herlev, Denmark

${ }^{4}$ Department of Biotechnology and Biomedicine, Technical University of

Denmark, Kongens Lyngby, Denmark

Full list of author information is available at the end of the article
} 


\section{Background}

Idiopathic pulmonary fibrosis (IPF), chronic obstructive pulmonary disease (COPD) and lung cancer are lung pathologies which are characterized by excessive accumulation of extracellular matrix (ECM) leading to loss of tissue homeostasis and progressive disease phenotype [1-3]. Biomarkers which reflect these processes may therefore play an important role in identifying patients with rapid disease progression. Decorin is a member of the small leucine-rich proteoglycan (SLRP) family and is one of the most abundant proteoglycans of the interstitial matrix. The protein is mainly secreted and deposited by fibroblasts. It consists of a single covalently attached N-terminal glycosaminoglycan (GAG) chain, composed of either dermatan or chondroitin sulfate, and 12 leucine-rich tandem repeats representing the protein core [4-6].

Due to its diverse ECM protein binding partners and its regulation of cell growth and cell differentiation, decorin has been named as "the guardian from the matrix" [7] recognizing the significance of decorin in tissue homeostasis. The main ECM binding partners are fibrillar collagens (type I, II, III and VI) and decorin has shown to play a role in the regulation of fibrillogenesis and stabilization of fibrils, and may act as a central player in collagen assembly/turnover and consequently tissue homeostasis [8, 9]. Supporting this, decorin knock-out in mice results in abnormal collagen fibril formation and enhanced collagen degradation [10].

In addition to playing a role in collagen fibril formation in the interstitial ECM, decorin sequesters multiple growth factors, such as TGF-beta and directly antagonizes several members of the receptor tyrosine kinase family, including the epidermal growth factor receptor (EGFR) and insulin-like growth factor receptor I (IGFIR) $[7,11-14]$. As a consequence, decorin regulates survival, migratory, proliferative and angiogenic signaling pathways.

Decorin's ability to modulate various signal transduction pathways has given it a valid reputation within cancer and several studies have revealed decorin as a tumor repressor which counteracts tumorigenic and angiogenic growth [15]. Furthermore, reduced decorin within the tumor stroma is a poor prognostic factor of invasive breast-, lung- and soft tissue cancers as well as in myeloma [5, 16-18].

Decorin appears to have a protective role in cancer and has also been shown to have anti-fibrotic properties. Fibrosis is characterized by an increased and disorganized deposition of ECM proteins resulting in loss of tissue and organ function. One of the key pro-fibrotic mediators is TGF-beta, a chemotactic factor for fibroblasts enhancing the synthesis of ECM proteins. As decorin is an inhibitor of TGF-beta, numerous studies have investigated the decorin's potential to block the fibrotic response and decorin has shown to reduce tissue fibrosis in kidney and lung in multiple disease models [19-21].

Increased ECM remodeling and protease-mediated degradation of ECM proteins is a well-documented and significant component of cancer pathology and lung fibrosis $[1-3,22]$. We hypothesize that degradation of decorin may have biomarker potential in these pathologies as degradation of decorin might inactivate and disrupt its anti-tumor and anti-fibrotic capabilities.

A decorin fragment was previously identified in human knee articular cartilage using mass spectrometry (MS/MS) [23]. The aim of this work was to develop a competitive enzyme-linked immunosorbent assay (ELISA) targeting the specific degraded fragment of decorin, identify the protease generating this fragment, and to investigate the biomarker potential of this fragment in serum from patients with various lung pathologies.

\section{Methods \\ Selection of peptides}

The following cleavage site $(\downarrow)$ on decorin was previously identified in human knee articular cartilage using mass spectrometry and published by Zhen et al. [23]:

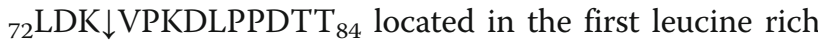
repeat of the protein.

In order to generate an antibody specific for the Nterminal of the cleavage fragment, a sequence of 10 amino acids adjacent to the site was chosen as the target: $\downarrow_{75} \mathrm{VPKDLPPDTT}_{84}$. This amino acid sequence was used to design the standard peptide. The sequence was blasted for homology to other human secreted extracellular matrix proteins using NPS@: Network Protein Sequence Analysis with the UniprotKB/Swiss-prot database [24].

Synthetic peptides used for monoclonal antibody production and validation of the ELISA assay were purchased from Chinese Peptide Company (Hangzhou, China) and Genscript (Piscataway, NJ, USA) and shown in Table 2. A biotinylated peptide (VPKDLPPDTT-biotin) was included as a coating peptide on streptavidin-coated ELISA plates. The specificity of the antibody was tested by including an elongated standard peptide with an additional amino acid added to the $\mathrm{N}$-terminal of the peptide sequence (KVPKDLPPDTT), as well as a non-sense standard peptide (DSSAPKAAQA) and a non-sense biotinylated coating peptide (biotin-DSSAPKAAQA) in the assay validation. The immunogenic peptide (VPKDLPPDTT-KLH) was generated by covalently cross-linking the standard peptide to Keyhole Limpet Hemocyanin (KLH) carrier protein using Succinimidyl 4-(N-maleimidomethyl)cyclohexane-1carboxylate, SMCC (Thermo Scientific, Waltham, MA, USA, cat.no. 22336). 


\section{Monoclonal antibody production}

Four to six week old Balb/C mice were immunized by subcutaneous injection of $200 \mu \mathrm{L}$ emulsified antigen containing $50 \mu \mathrm{g}$ immunogenic peptide (VPKDLPPDTT-KLH) mixed with Freund's incomplete adjuvant (Sigma-Aldrich, St. Louis, MO, USA). Consecutive immunizations were performed at 2-week intervals until stable sera titer levels were reached. The mouse with the highest titer rested for four weeks and was then boosted with $50 \mu \mathrm{g}$ immunogenic peptide in $100 \mu \mathrm{L} 0.9 \% \mathrm{NaCl}$ solution intravenously. Hybridoma cells were produced by fusing spleen cells with SP2/0 myeloma cells as previously described [25]. The resultant hybridoma cells were then cultured in 96-well microtiter plates and standard limited dilution was used to secure monoclonal growth. The supernatants were screened for reactivity using the biotinylated peptide (VPKDLPPDTT-biotin) as coating agent in the competitive immunoassays.

\section{Clone characterization}

The reactivity of the monoclonal antibodies was evaluated by displacement using human serum samples and the standard peptide (VPKDLPPDTT) in a preliminary ELISA using $10 \mathrm{ng} / \mathrm{mL}$ biotinylated coating peptide on streptavidin-coated microtiter plates (Roche, Basel, Switzerland, cat. \#11940279) and the supernatant from the antibody producing monoclonal hybridoma cells. The clone with the best reactivity towards the standard peptide was purified using protein-G-columns according to the manufacturer's instructions (GE Healthcare Life Sciences, Little Chalfont, UK, cat. \#17-0404-01).

\section{Cleavage of decorin in vitro}

Reconstituted human recombinant decorin (ACRO Biosystems, Newark, DE, USA, cat. \# DE1-HS223) was diluted to a final concentration of $100 \mu \mathrm{g} / \mathrm{mL}$ in cathepsin buffer (100 mM sodium phosphate, $2 \mathrm{mM} \mathrm{DTT,} \mathrm{0.01 \%} \mathrm{Brij-35,}$ $\mathrm{pH}$ 7.4), MMP-buffer (50 mM Tris-HCL, $200 \mathrm{mM} \mathrm{NaCl}$, $10 \mathrm{mM} \mathrm{CaCl}, 100 \mu \mathrm{M}$ ZnAc, pH 7.5) or ADAMTS-5 buffer $(50 \mathrm{mM}$ Tris, $100 \mathrm{mM} \mathrm{NaCl}, 5 \mathrm{mM} \mathrm{CaCl}, 0.05 \%$ Brij-35, pH 7.5). The solutions incubated at $37^{\circ} \mathrm{C}$ for $1 \mathrm{~h}$, $24 \mathrm{~h}$ and $72 \mathrm{~h}$ with or without the addition of the following proteases: Cathepsin-S (Merckmillipore, cat. \# 219343), cathepsin-L (Merckmillipore, cat. \# 219402), APMA activated MMP-2 (Biocol, cat. \# II.5), MMP-9 (Giotto, cat. \# G04MP09C) and ADAMTS-5 (R\&D systems, cat. \# 2198$\mathrm{AD})$. Cathepsins and MMPs were added to a final concentration of $2 \mu \mathrm{g} / \mathrm{mL}$ and ADAMTS-5 to a final concentration of $10 \mu \mathrm{g} / \mathrm{mL}$. A positive control protein with known cleavage by the above proteases was included. The reaction was stopped by adding E-64 (final concentration of $1 \mathrm{uM}$ ) to cathepsins solutions and EDTA to the MMP solutions (final concentration of $1 \mathrm{uM}$ ) and ADAMTS-5 solutions (final concentration of $5 \mathrm{uM}$ ). Cathepsin-, MMP- and ADAMTS- 5 buffer with relevant proteases were included as controls. Samples were stored at $-80{ }^{\circ} \mathrm{C}$ until analysis. The cleavage of decorin was confirmed by silverstaining according to the manufacturer's instructions (SilverXpress ${ }^{\circ}$, Invitrogen, cat. \#LC6100) and coomassie blue (data not shown).

DCN-CS (decorin degraded by cathepsin-S) ELISA protocol Optimal incubation -buffer, -time and -temperature, as well as the optimal concentrations of antibody and coating peptide were determined and the finalized DCN-CS competitive ELISA protocol was as follows:

A 96-well streptavidin-coated microtiter plate was coated with $2.5 \mathrm{ng} / \mathrm{mL}$ biotinylated coating peptide dissolved in assay buffer $(50 \mathrm{mM}$ Tris-BTB, $4 \mathrm{~g} / \mathrm{L} \mathrm{NaCl}$, $\mathrm{pH}$ 8.0) and incubated for $30 \mathrm{~min}$. at $20{ }^{\circ} \mathrm{C}$ in darkness shaking $(300 \mathrm{rpm})$. Twenty $\mu \mathrm{L}$ standard peptide or prediluted serum (1:4) were added to appropriate wells, followed by the addition of $100 \mu \mathrm{L}$ monoclonal antibody dissolved in assay buffer to a concentration of $30 \mathrm{ng} / \mathrm{mL}$ to each well and incubated $20 \mathrm{~h}$ at $5{ }^{\circ} \mathrm{C}$ in darkness shaking (300 rpm). One hundred $\mu \mathrm{L}$ of goat anti-mouse PODconjugated IgG antibody (Thermo Scientific, Waltham, MA, USA, cat. \#31437) diluted 1:6000 in assay buffer to obtain a final concentration of $130 \mathrm{ng} / \mathrm{mL}$ was added to each well and incubated $1 \mathrm{~h}$ at $20{ }^{\circ} \mathrm{C}$ in darkness shaking. All incubation steps were followed by five washes in washing buffer $(20 \mathrm{mM}$ Tris, $50 \mathrm{mM} \mathrm{NaCl}, \mathrm{pH} 7.2)$. Finally, $100 \mu \mathrm{L}$ tetramethylbenzidine (TMB) (cat. 438OH, KemEn-Tec Diagnostics, Denmark) was added to each well and the plate was incubated for $15 \mathrm{~min}$ at $20{ }^{\circ} \mathrm{C}$ in darkness shaking. The enzymatic reaction was stopped by adding $0.18 \mathrm{M} \mathrm{H} 2 \mathrm{SO} 4$ and absorbance was measured at $450 \mathrm{~nm}$ with $650 \mathrm{~nm}$ as reference. A calibration curve was plotted using a 4-parameter logistic curve fit. Data were analyzed using the SoftMax Pro v.6.3 software.

\section{Technical evaluation of the DCN-CS ELISA}

To evaluate the technical performance of the DCN-CS ELISA, the following validation tests were carried out: Inter- and intra-assay variation, linearity, lower limit of detection, upper limit of detection, lower limit of quantification, analyte stability (freeze/thaw and storage) and interference.

The inter- and intra-assay variation was determined by ten independent runs on different days using ten quality control samples covering the detection range, with each run consisting of double-determinations of the samples. The ten quality control samples consisted of: two human serum samples, one sheep serum sample, one fetal calve serum sample, four human serum samples spiked with 
standard peptide and two samples with standard peptide in buffer. Intra-assay variation was calculated as the mean coefficient of variance (CV\%) within plates and the inter-assay variation was calculated as the mean $\mathrm{CV} \%$ between the ten individual runs. To assess linearity of the assay, two-fold dilutions of human serum samples were performed and dilution linearity was calculated as a percentage of recovery of the un-diluted sample. The lower limit of detection (LLOD) was determined from 21 measurements using assay buffer as sample and was calculated as the mean + three standard deviations. The upper limit of detection (ULOD) was determined from ten independent runs of the highest standard peptide concentration and was calculated as the mean backcalibration calculation + three standard deviations. The lower limit of quantification (LLOQ) was determined from three independent runs of a serum sample diluted stepwise and determined as the highest DCN-CS level quantifiable in serum with a coefficient of variation below 30\%. Analyte stability was first determined by the effect of repeated freeze/thaw of serum samples by measuring the DCN-CS level in three human serum samples in four freeze/thaw cycles. The freeze/thaw recovery was calculated with the first cycle as reference. Second, analyte stability in relation to storage was determined by a $24 \mathrm{~h}$ study performed at $4{ }^{\circ} \mathrm{C}$ or $20{ }^{\circ} \mathrm{C}$. The DCN-CS level in three human serum samples was measured after $0 \mathrm{~h}, 2 \mathrm{~h}, 4 \mathrm{~h}$ and $24 \mathrm{~h}$ of storage and recovery was calculated with samples stored at $-20{ }^{\circ} \mathrm{C}$ as reference. Interference was determined by adding a low/high content of hemoglobin $(0.155 / 0.310 \mathrm{mM})$, lipemia/lipids $(4.83 / 10.98 \mathrm{mM})$ and biotin $(30 / 90 \mathrm{ng} / \mathrm{mL})$ to a serum sample of known concentration. Recovery percentage was calculated with the normal serum sample as reference.

\section{Clinical validation of DCN-CS}

Patient serum samples consisted of three different cohorts. Cohort 1 was obtained from the commercial vendor ProteoGenex (Culver City, CA, USA) and included patients with non-small cell lung cancer (NSCLC), IPF, COPD and colonoscopy-negative controls with no symptomatic or chronic disease. A panel of healthy donors acquired from the commercial vendor Valley Biomedical (Winchester, VA, USA) were included as controls (Table 1).

Cohort 2 consisted of lung cancer patients acquired from the commercial vendor Asterand (Detroit, MI, USA) and healthy control serum samples obtained from a Danish study population.

Cohort 3 was a combination of serum samples from patients diagnosed with IPF (baseline samples, CTgov reg. NCT00786201) and healthy control serum samples acquired from the commercial vendor Valley Biomedical (Winchester, VA, USA) (Table 1).

\section{Statistical analysis}

The level of DCN-CS in serum samples was compared using one-way ANOVA adjusted for Tukey's multiple comparisons test (parametric data), Kruskal-Wallis adjusted for Dunn's multiple comparisons test (non-parametric data) or unpaired, two-tailed Mann-Whitney test. D'Agostino-Pearson omnibus test was used to assess the normality of the data. The diagnostic power was investigated by the area under the receiver operating characteristics (AUROC). Sensitivity and specificity were determined for cut-off values based on the ROC curves. The cut-off values should be regarded as a preliminary estimated cut-off point applied to achieve the reported maximized sensitivity and specificity.

Unless otherwise stated, data are shown as Tukey box plots, where the boxes represent the 25th, 50th and 75th percentiles. The whiskers represent the lowest and highest value, except outliers, which are higher than 1.5 times the 75th percentile or lower than 1.5 times the 25 th percentile. $P$-values $<0.05$ were considered significant. Statistical analyses were performed using GraphPad Prism version 6 (GraphPad Software, Inc., CA, USA) and MedCalc Statistical Software version 12 (MedCalc Software, Ostend, Belgium). Graphs were designed using GraphPad Prism version 6 (GraphPad Software, Inc., CA, USA).

\section{Results}

\section{Specificity of the DCN-CS ELISA assay}

The target sequence, ${ }_{75} \mathrm{VPKDLPPDTT}_{84}$, was blasted for homology to other human secreted extracellular matrix proteins using NPS@: Network Protein Sequence Analysis with the UniprotKB/Swiss-prot database. The target sequence was found to be unique to human decorin when compared to other secreted ECM proteins. Allowing one amino acid mismatch, two secreted extracellular matrix proteins, Wnt-11 and Podocan, were identified with mismatches at the 6th and 4th position, respectively (Table 2). There was no reactivity against the sequence of Wnt-11, whereas some reactivity was observed against Podocan (data not shown). However, the affinity of the antibody was approximately 10 times higher for decorin than the podocan peptide. At the same time, it is unknown whether podocan will be cleaved in vivo between the exact two amino acids creating this peptide fragment. Furthermore, decorin has been shown to be the most abundant proteoglycan in human adult skin [6] decreasing the likelihood of reactivity towards podocan in biological samples.

The specificity of the competitive DCN-CS ELISA was evaluated by analyzing the reactivity towards the standard peptide, a non-sense peptide, an elongated peptide and using a non-sense biotinylated coating peptide. All peptide sequences are shown in Table 2 and results are shown in Fig. 1 . The antibody only reacted with the standard peptide 
Table 1 Clinical sample overview and patients demographics

\begin{tabular}{|c|c|c|c|c|c|c|c|c|}
\hline Cohort & Samples & $\begin{array}{l}\text { No. of } \\
\text { subjects }\end{array}$ & $\begin{array}{l}\text { Mean age } \\
\text { (range) }\end{array}$ & $\begin{array}{l}\text { Gender, \% } \\
\text { females }\end{array}$ & $\begin{array}{l}\text { Tumor } \\
\text { stage I }\end{array}$ & $\begin{array}{l}\text { Tumor } \\
\text { stage II }\end{array}$ & $\begin{array}{l}\text { Tumor } \\
\text { stage III }\end{array}$ & $\begin{array}{l}\text { Tumor } \\
\text { stage IV }\end{array}$ \\
\hline 1 & NSCLC patients & 8 & $61(47-77)$ & 12.8 & 1 & 2 & 3 & 2 \\
\hline 1 & IPF patients & 8 & $74(55-82)$ & 62.5 & - & - & - & - \\
\hline 1 & COPD patients & 8 & $75(69-82)$ & 50.0 & - & - & - & - \\
\hline 1 & Colonoscopy-negative controls & 8 & $55(44-65)$ & 75.0 & - & - & - & - \\
\hline 1 & Healthy controls & 20 & $34(20-51)$ & 10.0 & - & - & - & - \\
\hline 2 & NSCLC patients ${ }^{a}$ & 12 & $60(47-80)$ & 25.0 & 5 & 2 & 4 & - \\
\hline 2 & SCLC patients & 8 & $61(54-82)$ & 25.0 & 3 & 1 & 4 & - \\
\hline 2 & Healthy controls & 43 & $71(60-82)$ & 100.0 & - & - & - & - \\
\hline 3 & IPF patients & 116 & $65(43-80)$ & 21.5 & - & - & - & - \\
\hline 3 & Healthy controls & 38 & $34(20-58)$ & 10.5 & - & - & - & - \\
\hline
\end{tabular}

${ }^{a}$ No tumor stage information of one patient

and the standard peptide clearly inhibited the signal in a dose-dependent manner compared to the other peptides. No detectable signal was observed when using the nonsense biotinylated coating peptide. These data suggest that the selected antibody exhibits high epitope specificity.

\section{Degradation by Cathepsin-S}

The ability of different proteases to generate the specific decorin fragment was investigated by incubating recombinant human decorin with cathepsin-S (Cat-S), Cathepsin-L (Cat-L), MMP-2, MMP-9 and ADAMTS-5. As shown in Fig. 2, Cat-S was able to generate decorin fragments in a time-dependent manner. Almost 6-fold higher decorin fragments were detected after incubating recombinant decorin with Cat-S for $24 \mathrm{~h}$. No cleavage was observed with Cat-L, MMP-9, MMP-2 and ADAMTS-5 up to $72 \mathrm{~h}$ of incubation (data not shown).

Together, these results show that Cat-S can generate the target peptide recognized by the antibody.

\section{Technical evaluation of the DCN-CS ELISA assay}

A series of technical validations were performed to further evaluate the DCN-CS ELISA. The different

Table 2 Synthetic peptides used for development and validation of the DCN-CS ELISA assay

\begin{tabular}{ll}
\hline Peptide name & Amino acid sequence \\
\hline Selection/standard peptide & VPKDLPPDTT \\
Immunogenic peptide & VPKDLPPDTT-KLH \\
Biotinylated coating peptide & VPKDLPPDTT-biotin \\
Elongated peptide & KVPKDLPPDTT \\
Non-sense selection peptide & DSSAPKAAQA \\
Non-sense coating peptide & biotin-DSSAPKAAQA \\
Wnt-11 peptide & VPKDLDIRPV \\
Podocan peptide & VPKHLPPALY \\
\hline
\end{tabular}

validation steps and DCN-CS performance are shown in Table 3. The measuring range (LLOD to ULOD) of the assay was determined to $1.2-345.3 \mathrm{ng} / \mathrm{mL}$ and the lower limit of quantification (LLOQ) was $5.3 \mathrm{ng} /$ $\mathrm{mL}$. The intra- and inter-assay variation was 3 and $13 \%$, respectively. The acceptance criterion was below $10 \%$ for the intra-assay variation and below $15 \%$ for the inter-assay variation and therefore acceptable. Human serum needed to be diluted 1:4 to obtain linearity and mean dilution recovery for pre-diluted human serum was $100 \%$. The analyte recovery in serum was $94 \%$ after 4 freeze/thaw cycles and after storage at $4{ }^{\circ} \mathrm{C}$ for $24 \mathrm{~h}$ the recovery was $87 \%$. The acceptance criterion was a recovery within $100 \% \pm 20 \%$. Analyte stability was also tested at $20{ }^{\circ} \mathrm{C}$ for 2,4 and $24 \mathrm{~h}$. The recovery after 2 and $4 \mathrm{~h}$ was $93 \%$ and $78 \%$, respectively. However after $24 \mathrm{~h}$ the analyte could not be recovered within the acceptance range (53\% recovery). These data indicate that the analyte in serum is stable at $4{ }^{\circ} \mathrm{C}$ and serum samples to be analyzed for DCN-CS should not be stored above this temperature for more than four hours. No interference was detected from either low or high contents of biotin, lipids or hemoglobin with recoveries ranging from 86 to $107 \%$. The acceptance criterion was a recovery within $100 \% \pm 20 \%$.

\section{Clinical evaluation - DCN-CS as a biomarker for fibrotic lung disorders}

DCN-CS were measured in serum samples from three independent cohorts including patients with lung cancer, IPF, COPD and healthy controls. The data are presented in Fig. 3. Results from cohort 1 show that DCN-CS was significantly elevated in serum from NSCLC $(p<0.0001)$ and IPF $(p<0.001)$ patients as compared to healthy controls. No significance was observed for COPD patients. The mean level of DCN-CS was also significantly higher in NSCLC patients compared to colonoscopy-negative 


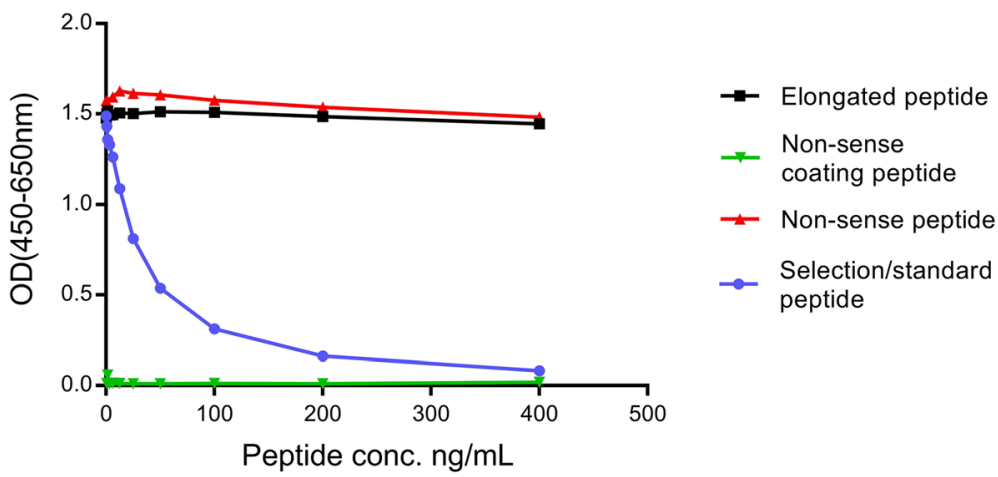

Fig. 1 Specificity of the DCN-CS monoclonal antibody. Monoclonal antibody reactivity towards the standard peptide (VPKDLPPDTT), the elongated peptide (KVPKDLPPDTT), a non-sense peptide (DSSAPKAAQA) and a non-sense coating peptide (biotin-DSSAPKAAQA) was tested for in the competitive DCN-CS ELISA assay. Signals are shown as optical density (OD) at $450 \mathrm{~nm}$ (subtracted the background at $650 \mathrm{~nm}$ ) as a function of peptide concentration

controls, IPF and COPD patients. Data from cohort 2 confirmed the findings from cohort 1: DCN-CS was significantly elevated in NSCLC and SCLC patients as compared to healthy controls $(p<0.0001)$. Cohort 3 included patients with IPF and confirmed the results observed in cohort 1; IPF patients had a significantly higher level of DCN-CS $(p<0.0001)$ as compared to healthy controls.

The area under the receiver operating characteristics (AUROC) was used to evaluate the discriminative power of DCN-CS in relation to NSCLC and IPF. NSCLC patients, IPF patients and healthy controls from all cohorts were pooled and grouped into 'NSCLC', 'IPF' and 'healthy controls'. As shown in Table 4, DCN-CS was able to discriminate between NSCLC patients and healthy controls with an AUROC of 0.96 (95\%CI: 0.90-0.99), $p<0.0001$ ) with a specificity of $100 \%$ and sensitivity of $90 \%$ for an estimated optimal cut-off value. Similarly, DCN-CS was able

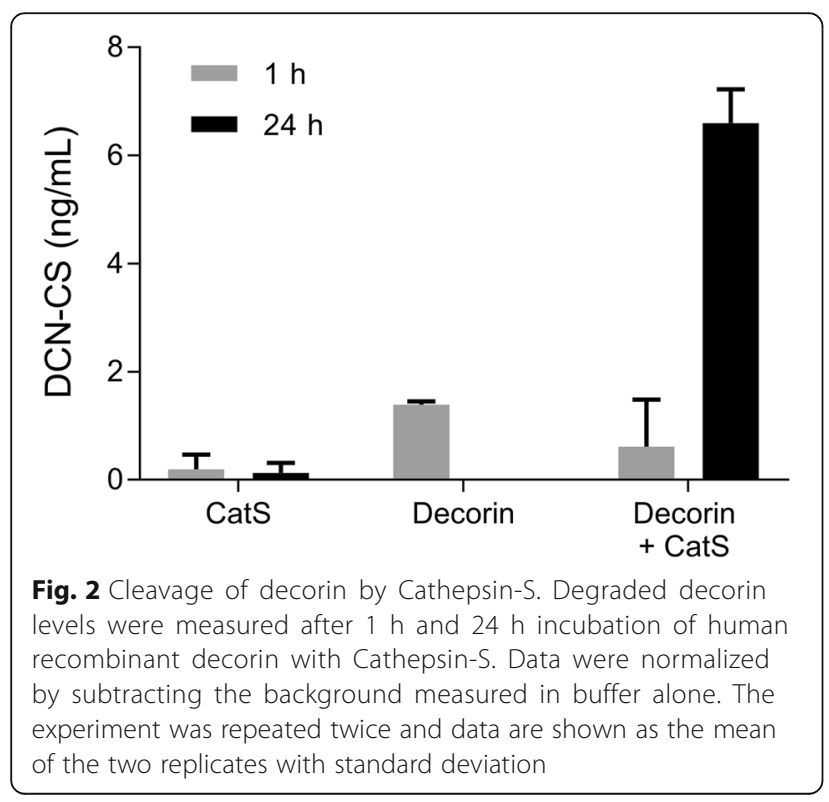

to identify IPF patients from healthy controls with an AUROC of 0.77 (95\%CI: 0.71-0.83), $p<0.0001$ ) with a specificity of $83 \%$ and sensitivity of $63 \%$ for an estimated optimal cut-off. The ROC curves are presented in Fig. 4.

These findings indicate that DCN-CS levels are able to separate patients with NSCLC and IPF from healthy controls with high diagnostic accuracy. Thus this specific fragment in serum has biomarker potential in fibrotic lung disorders such as lung cancer and IPF.

\section{Discussion}

The present study describes the development and biological validation of a technically robust competitive ELISA assay quantifying a Cat-S degraded fragment of decorin in serum. The main findings of this study were: 1) the fragment was significantly elevated in lung cancer and IPF patients compared to healthy controls 2) the fragment was detectable in serum and 3) the assay was technically robust and specific towards a unique Cat-S degraded fragment of decorin, DCN-CS. To our knowledge

Table 3 Technical validation data of the DCN-CS ELISA assay

\begin{tabular}{ll}
\hline Tecnical validation step & DCN-CS performance \\
\hline Detection range (LLOD-ULOD) & $1.2-345.3 \mathrm{ng} / \mathrm{mL}$ \\
Lower limit of quantification (LLOQ) & $5.3 \mathrm{ng} / \mathrm{mL}$ \\
Intra-assay variation & $3 \%$ \\
Inter-assay variation & $13 \%$ \\
Dilution of serum samples & $1: 4$ \\
Dilution recovery (1:4 pre-dilution) ${ }^{\mathrm{a}}$ & $100 \%(82-113 \%)$ \\
Freeze/thaw recovery $(4 \mathrm{cycles})^{\mathrm{a}}$ & $94 \%(90-97 \%)$ \\
Analyte stability up to $24 \mathrm{~h}, 4^{\circ} \mathrm{C}^{\mathrm{a}}$ & $87 \%(86-90 \%)$ \\
Interference Lipids, low/high $^{\text {Interference Biotin, low/high }}$ & $107 \% / 86 \%$ \\
Interference Hemoglobin, low/high & $100 \% / 100 \%$
\end{tabular}

Percentages are reported as mean with range shown in brackets 
Cohort 1

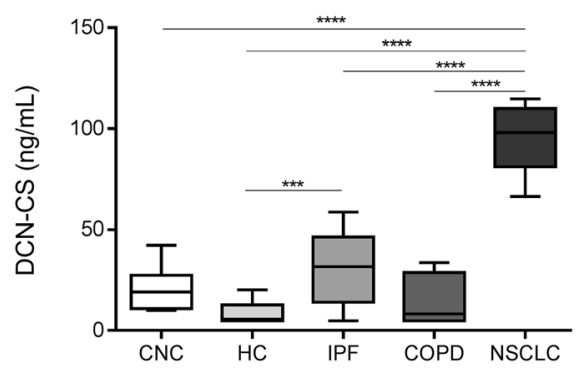

Cohort 3

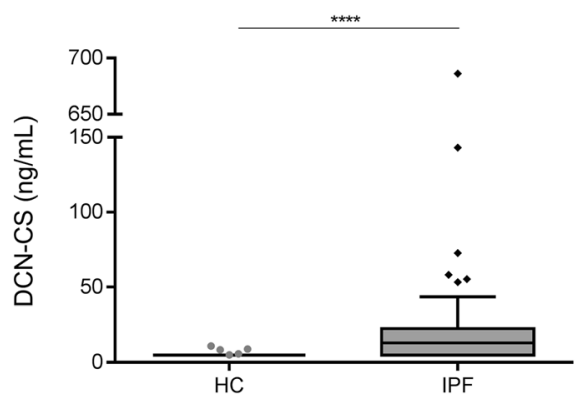

Cohort 2

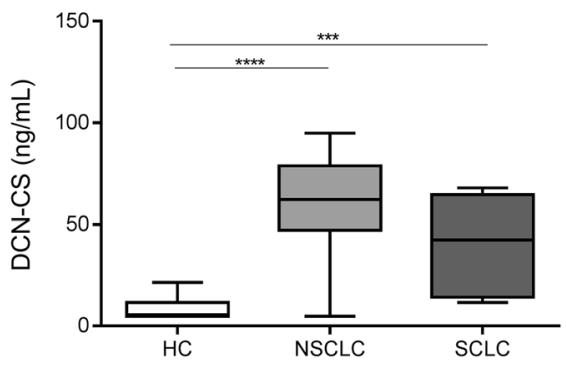

Fig. 3 Serum DCN-CS levels in patients with fibrotic lung disorders. Serum DCN-CS was assessed in three independent cohorts: Cohort 1 included patients with NSCLC $(n=8), \operatorname{IPF}(n=8), \operatorname{COPD}(n=8)$, colonoscopy-negative controls $(\mathrm{CNC})(n=8)$ and a panel of healthy controls $(\mathrm{HC})(n=20)$. Data were compared using one-way ANOVA adjusted for Tukey's multiple comparisons test. Cohort 2 consisted of patients with NSCLC ( $n=12$ ), SCLC $(n=8)$ and healthy controls $(\mathrm{HC})(n=43)$. Data were compared using Kruskal-Wallis adjusted for Dunn's multiple comparisons test. Cohort 3 comprised serum samples from patients diagnosed with IPF $(n=116)$ and healthy controls $(H C)(n=38)$. Groups were compared using unpaired, two-tailed Mann-Whitney test. Data are shown as Tukey box plots. Significance levels: ${ }^{* *}: p<0.001$ and ${ }^{* * *}: p<0.0001$

this is the first biological validation of a specific decorin fragment in fibrotic lung disorders.

Decorin has been shown to play a protective role in cancer and fibrosis due to its ability to modulate various signal transduction pathways and sequester TGF-beta via direct binding [5]. This has led to the speculation that degradation of decorin may induce the development of cancer and fibrotic diseases by disrupting the binding to its binding partners. The lungs are an organ with a large amount of interstitial matrix and we have shown that patients with fibrotic lung disorders, such as cancer and IPF, have an increased level of degraded decorin. Cat-S is produced in both tumor cells and tumorassociated macrophages and has been associated with growth, angiogenesis and metastasis in different cancer types [26-28]. The interaction between these two proteins might give rise to a certain pathology where the interstitial matrix is involved and this interaction can be measured by the assay presented here.

The data suggest that Cat-S specific degradation of decorin has a relevant role in the pathology of lung cancer and IPF. We hypothesize that increased degradation of decorin triggers a fibrotic response both by inhibiting binding of TGF-beta to decorin which will result in the release of excessive amounts of TGF-beta but also by disrupting proper collagen fibril formation leading to loss of homeostasis in the interstitial matrix. Several studies have shown that disrupting the normal collagen turnover balance leads to fibrosis and cancer [1-3, 22]. Why the specific decorin fragment was not significantly elevated in patients with COPD is to be investigated further.

Based on the high elevated level of degraded decorin in patients compared to healthy controls, the present assay can provide a novel non-invasive clinical tool in

Table 4 Discriminative performance of DCN-CS in NSCLC and IPF

\begin{tabular}{|c|c|c|c|c|c|}
\hline & Cut-off value (ng/mL) & Sensitivity & Specificity & AUROC (95\% Cl) & $p$-value \\
\hline NSCLC vs. healthy controls & 21.5 & 90.0 & 100.0 & $0.96(0.90-0.99)$ & $<0.0001$ \\
\hline IPF vs. healthy controls & 8.9 & 62.9 & 82.7 & $0.77(0.71-0.83)$ & $<0.0001$ \\
\hline
\end{tabular}



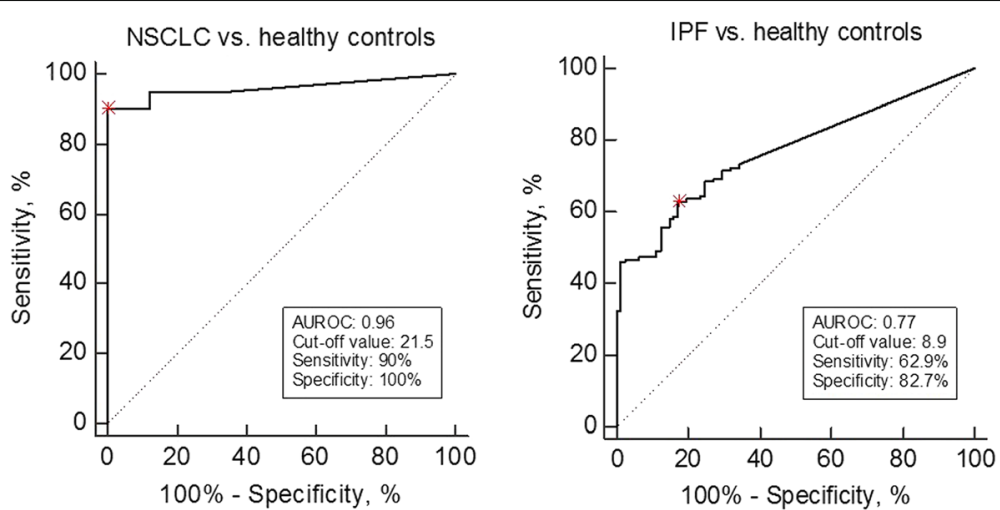

Fig. 4 ROC curve analysis. Roc curve analysis was used to evaluate the ability of DCN-CS to discriminate between patients and healthy controls. The preliminary estimated cut-off values for the reported sensitivity/specificity are marked with a red asterix

lung cancer and IPF. The fact that the AUC was higher for lung cancer compared to IPF, suggests that this pathological event seems to be more associated with lung cancer than IPF and DCN-CS could serve as a potential diagnostic biomarker for lung cancer. In relation to IPF, the data suggests other clinical uses of this biomarker, such as prognosis and/or prediction. This needs to be further investigated in larger clinical studies. Evidence suggests that decorin fragments can function as pro-inflammatory signaling molecules, so-called damageassociated molecular patterns (DAMPs), capable of inducing an inflammatory response [5, 29]. High levels of degraded decorin might therefore indicate a severe inflammatory state. However further studies are needed to investigate whether the DCN-CS fragment functions as a DAMP.

The DCN-CS assay was shown to be technically robust, with low values of LLOD, intra- and inter variation and acceptable dilution recovery, interference and analyte stability at $4{ }^{\circ} \mathrm{C}$. The fact that the assay did not detect the elongated peptide nor a non-sense peptide indicates that the monoclonal antibody is specific towards the cleavage site between amino acid 74 and 75 located in the first leucine-rich repeat of decorin. This was supported by data showing that DCN-CS was able to quantify high levels of the fragment after in vitro cleavage of decorin with Cat-S. Reactivity towards intact decorin was minimal further demonstrating that this assay does not measure total protein but a specific degraded fragment.

The target peptide fragment was originally identified by Zhen et al. [23] in human articular cartilage digested with ADAMTS-5. We have shown that this fragment is generated by Cat-S and not by Cat-L, MMP- $2 / 9$ or ADAMTS-5 in vitro using recombinant decorin. The fact that ADAMTS-5 degradation could not generate the target peptide fragment under our conditions, indicates that other proteases may have to cleave the protein before ADAMTS-5 can generate this fragment. Imai et al. [30] have examined the ability of different MMP'-s to cleave decorin and found that MMP-2, MMP-3 and MMP-7 were able to generate degradation fragments. None of these fragments correspond to our target fragment which supports our findings that the DCN-CS fragment is specifically generated by Cat-S and not MMP's. This is important since different protein fragments may reflect different pathological events [31, 32], i.e. Cat-S degraded decorin might reflect one disease state whereas MMP-degraded decorin reflects other disease activity patterns. As the present assay enables quantification of a specific neo-epitope it might be superior to other commercial assays in which decorin is quantified but the precise epitope is not known. These quantification capabilities also increases the biomarker potential as it may reflect a direct pathological event, such as fibrosis.

The diagnostic validation of DCN-CS in the present study is limited by relatively small population sizes and cross-sectional designs and clinical information was limited. In addition, it was not easy to match cases and controls according to age, gender and tobacco consumption in this preliminary study which therefore could be confounding factors. However the fact that we could confirm the findings in independent cohorts, increases the validity. Larger longitudinal studies are needed to fully validate the potential of DCN-CS as a diagnostic and/or prognostic biomarker in fibrotic lung diseases.

\section{Conclusion}

In conclusion, we have developed a technically robust competitive ELISA assay targeting a specific Cat-S degraded fragment of decorin (DCN-CS). The level of DCN-CS was significantly higher in patients with lung cancer and IPF compared to healthy controls, suggesting a pathological role of degraded decorin in these lung disorders.

\section{Abbreviations}

ADAMTS: A disintegrin and metalloproteinase with thrombospondin motifs; AUROC: Area under the receiver operating characteristics; Cat-L: Cathepsin L; 
Cat-S: Cathepsin-S; COPD: Chronic obstructive pulmonary disease; DAMP: Damage-associated molecular pattern; DCN-CS: Decorin degraded by cathepsin-S; ECM: Extracellular matrix; EGFR: Epidermal growth factor receptor; ELISA: Enzyme-linked immunosorbent assay; GAG: Glycosaminoglycan; IPF: Idiopathic pulmonary fibrosis; IGF-IR: Insulin-like growth factor receptor; LLOD: Lower limit of detection; LLOQ: Lower limit of quantification; NSCLC: Non-small cell lung cancer; MMP: Matrix metalloproteinase; SLRP: Small leucine-rich proteoglycan; ULOD: Upper limit of detection

\section{Acknowledgements}

We acknowledge the Danish Science Foundation ("Den Danske Forskningsfond").

\section{Availability of data and material}

The datasets used and analysed during the current study are available from the corresponding author on reasonable request.

\section{Funding}

Not applicable

\section{Authors' contributions}

SNK was the main author of the manuscript. SNK carried out the measurements, data analysis and statistical analysis in discussion with CLB and NW. BD, CB and $M C$ were responsible for designing and conducting the clinical IPF study. $\mathrm{SB}, \mathrm{MK}$ and DJL supervised the entire project and experimental work and had a significant role in defining the hypotheses. All authors participated in data interpretation and critical revised and approved the final manuscript.

\section{Ethics approval and consent to participate}

For the clinical IPF study (CTgov reg. NCT00786201) the following ethic committee approved the study: Sterling Institutional Review Board, Sterling Independent Services, Inc. (Atlanta). The healthy control serum samples (cohort 2) were obtained from a Danish study population approved by The National Committee on Health Research Ethics (Denmark). According to Danish law additional ethical approval for measuring biochemical biomarkers in previously collected samples is not required. For the samples obtained from the commercial vendors Proteogenex, Asterand and Valley Biomedical, appropriate Institutional Review Board/Independent Ethical Committee approved sample collection and all patients filed informed consent.

\section{Consent for publication}

Not applicable.

\section{Competing interests}

C.L. Bager, N. Willumsen, D.J. Leeming and M.A. Karsdal are employed at Nordic Bioscience A/S which is a company involved in discovery and development of biochemical biomarkers. M.A. Karsdal owns stocks at Nordic Bioscience. M. Curran, B Dasgupta and C. Brodmerkel are employees of Janssen R\&D LLC. and own stock in Johnson \& Johnson. S.N. Kehlet and S. Brix reports no conflict of interest.

\section{Publisher's Note}

Springer Nature remains neutral with regard to jurisdictional claims in published maps and institutional affiliations.

\section{Author details}

${ }^{1}$ Nordic Bioscience A/S, Herlev, Denmark. ${ }^{2}$ Proscion A/S, Herlev, Denmark. ${ }^{3}$ Janssen Pharmaceutical Companies of J \& J, LLC, Springhouse, PA, USA. ${ }^{4}$ Department of Biotechnology and Biomedicine, Technical University of Denmark, Kongens Lyngby, Denmark.

\section{Received: 14 February 2017 Accepted: 2 August 2017}

Published online: 09 August 2017

\section{Reference list}

1. Bonnans C, Chou J, Werb Z. Remodelling the extracellular matrix in development and disease. Nat Rev Mol Cell Biol. 2014;15:786-801. doi:10. 1038/nrm3904.

2. Egeblad M, Rasch MG, Weaver VM. Dynamic interplay between the collagen scaffold and tumor evolution. Curr Opin Cell Biol. 2010;22:697-706.

3. Karsdal MA, Nielsen MJ, Sand JM, Henriksen K, Genovese F, Bay-Jensen $A-C$, et al. Extracellular matrix remodeling: the common denominator in connective tissue diseases. Possibilities for evaluation and current understanding of the matrix as more than a passive architecture, but a key player in tissue failure. Assay Drug Dev Technol. 2013;11:70-92. doi:10.1089/adt.2012.474.

4. Krusius T, Ruoslahti E. Primary structure of an extracellular matrix proteoglycan core protein deduced from cloned cDNA. Proc Natl Acad Sci U S A. 1986;83: 7683-7. doi:10.1073/pnas.83.20.7683.

5. Järvinen TAH, Prince S. Decorin: a growth factor antagonist for tumor growth inhibition. Biomed Res Int. 2015;2015:654765. doi:10.1155/2015/654765.

6. Li Y, Liu Y, Xia W, Lei D, Voorhees JJ, Fisher GJ. Age-dependent alterations of decorin glycosaminoglycans in human skin. Sci Rep. 2013;3:2422. doi:10, 1038/srep02422.

7. Neill T, Schaefer L, lozzo RV. Decorin: a guardian from the matrix. Am J Pathol. 2012;181:380-7. doi:10.1016/j.ajpath.2012.04.029.

8. Sofeu Feugaing DD, Götte M, Viola M. More than matrix: the multifaceted role of decorin in cancer. Eur J Cell Biol. 2013;92:1-11. doi:10.1016/j.jck.2012.08.004.

9. Neame PJ, Kay CJ, McQuillan DJ, Beales MP, Hassell JR. Independent modulation of collagen fibrillogenesis by decorin and lumican. Cell Mol Life Sci. 2000;57:859-63.

10. Danielson KG, Baribault H, Holmes DF, Graham H, Kadler KE, lozzo RV. Targeted disruption of decorin leads to abnormal collagen fibril morphology and skin fragility. J Cell Biol. 1997;136:729-43.

11. Yamaguchi Y, Mann DM, Ruoslahti E. Negative regulation of transforming growth factor-beta by the proteoglycan decorin. Nature. 1990;346:281-4. doi:10.1038/346281a0

12. Schönherr E, Sunderkötter C, lozzo RV, Schaefer L. Decorin, a novel player in the insulin-like growth factor system. J Biol Chem. 2005;280:15767-72.

13. Iozzo RV, Moscatello DK, McQuillan DJ, Eichstetter I. Decorin is a biological ligand for the epidermal growth factor receptor. J Biol Chem. 1999;274:4489-92.

14. Iozzo RV, Buraschi S, Genua M, Xu SQ, Solomides CC, Peiper SC, et al. Decorin antagonizes IGF receptor I (IGF-IR) function by interfering with IGF-IR activity and attenuating downstream signaling. J Biol Chem. 2011;286:34712-21.

15. Neill T, Schaefer L, lozzo R V. Oncosuppressive functions of decorin. Mol Cell Oncol. 2015;2:e975645. doi:10.4161/23723556.2014.975645.

16. Bozoky B, Savchenko A, Guven H, Ponten F, Klein G, Szekely L. Decreased decorin expression in the tumor microenvironment. Cancer Med. 2014;3:485-91.

17. Boström $P$, Sainio $A$, Kakko $T$, Savontaus $M$, Söderström $M$, Järveläinen $H$, Localization of decorin gene expression in normal human breast tissue and in benign and malignant tumors of the human breast. Histochem Cell Biol. 2013;139:161-71.

18. Huang SY, Lin HH, Yao M, Tang JL, Wu SJ, Hou HA, et al. Higher decorin levels in bone marrow plasma are associated with superior treatment response to novel agent-based induction in patients with newly diagnosed myeloma - a retrospective study. PLoS One. 2015;10:e0137552.

19. Isaka Y, Brees DK, Ikegaya K, Kaneda Y, Imai E, Noble NA, et al. Gene therapy by skeletal muscle expression of decorin prevents fibrotic disease in rat kidney. Nat Med. 1996;2:418-23. doi:10.1038/nm0496-418.

20. Kolb M, Margetts PJ, Galt T, Sime PJ, Xing Z, Schmidt M, et al. Transient transgene expression of decorin in the lung reduces the fibrotic response to bleomycin. Am J Respir Crit Care Med. 2001;163 3 1:770-7.

21. Kolb M, Margetts PJ, Sime PJ, Gauldie J. Proteoglycans decorin and biglycan differentially modulate TGF-beta-mediated fibrotic responses in the lung. Am J Physiol Heart Circ Physiol. 2001;280:L1327-34. http://www.ncbi.nlm. nih.gov/pubmed/11350814

22. Lu P, Weaver VM, Werb Z. The extracellular matrix: a dynamic niche in cancer progression. J Cell Biochem. 2012;196:395-406.

23. Zhen EY, Brittain IJ, Laska DA, Mitchell PG, Sumer EU, Karsdal MA, et al. Characterization of metalloprotease cleavage products of human articular cartilage. Arthritis Rheum. 2008;58:2420-31.

24. Combet C, Blanchet C, Geourjon C, Deléage G. NPS@: network protein sequence analysis. Trends Biochem Sci. 2000;25:147-50. http://www.ncbi. nlm.nih.gov/pubmed/10694887. Accessed 27 May 2016

25. Gefter ML, Margulies DH, Scharff MD. A simple method for polyethylene glycol-promoted hybridization of mouse myeloma cells. Somatic Cell Genet. 1977:3:231-6.

26. Yixuan $Y$, Kiat $L S$, Yee $C L$, Huiyin $L$, Yunhao $C$, Kuan $C P$, et al. Cathepsin $S$ mediates gastric cancer cell migration and invasion via a putative network of metastasis-associated proteins. J Proteome Res. 2010;9:4767-78.

27. Fan $\mathrm{Q}$, Wang $X$, Zhang $\mathrm{H}, \mathrm{Li}$ C, Fan J, Xu J. Silencing cathepsin $\mathrm{S}$ gene expression inhibits growth, invasion and angiogenesis of human 
hepatocellular carcinoma in vitro. Biochem Biophys Res Commun. 2012;425:703-10.

28. Sevenich L, Bowman RL, Mason SD, Quail DF, Rapaport F, Elie BT, et al. Analysis of tumour- and stroma-supplied proteolytic networks reveals a brain-metastasis-promoting role for cathepsin S. Nat Cell Biol. 2014;16:87688. doi:10.1038/ncb3011.

29. Schaefer L. Complexity of danger: the diverse nature of damage-associated molecular patterns. J Biol Chem. 2014;289:35237-45.

30. Imai K, Hiramatsu A, Fukushima D, Pierschbacher MD, Okada Y. Degradation of decorin by matrix metalloproteinases: identification of the cleavage sites, kinetic analyses and transforming growth factor-beta1 release. Biochem J. 1997;322(Pt 3):809-14.

31. Karsdal MAA, Henriksen K, Leeming DJJ, Mitchell P, Duffin K, Barascuk N, et al. Biochemical markers and the FDA critical path: how biomarkers may contribute to the understanding of pathophysiology and provide unique and necessary tools for drug development. Biomarkers. 2009;14:181-202. doi:10.1080/13547500902777608.

32. Karsdal MA, Henriksen K, Leeming DJ, Woodworth T, Vassiliadis E, BayJensen AC. Novel combinations of post-translational modification (PTM) neo-epitopes provide tissue-specific biochemical markers-are they the cause or the consequence of the disease? Clin Biochem. 2010;43:793-804.

\section{Submit your next manuscript to BioMed Central} and we will help you at every step:

- We accept pre-submission inquiries

- Our selector tool helps you to find the most relevant journal

- We provide round the clock customer support

- Convenient online submission

- Thorough peer review

- Inclusion in PubMed and all major indexing services

- Maximum visibility for your research

Submit your manuscript at www.biomedcentral.com/submit 